\title{
Changing Concept of the Prevalence of Eosinophilic Esophagitis: Visible and Hidden Patients
}

\author{
Hyuk Lee \\ Division of Gastroenterology, Department of Medicine, Samsung Medical Center, Sungkyunkwan University School of Medicine, Seoul, \\ Korea
}

See "Prevalence of Eosinophilic Esophagitis in Adult Patients with Upper Gastrointestinal Symptoms in a Locality in Upper Egypt" by Magdy Fouad, Yasser Mahrous Fouad, Hamdy Ahmed Mokareb, et al., on page 357-361.

Eosinophilic esophagitis is a chronic inflammatory esophageal disease first reported by Landres et al. in 1978, and its characteristic clinical outcome was described later by Attwood et al. ${ }^{1,2}$ Several clinical symptoms arise from esophageal luminal stenosis caused by inflammation and edema, limited luminal expansion caused by remodeling, and stenosis caused by contraction and twitching of the esophageal muscle. The main mechanism known hitherto is chronic Th2 response to food antigens. ${ }^{3}$

Despite the fact that eosinophilic esophagitis can occur in different regions worldwide, its prevalence is relatively higher in the United States, Western Europe, and Australia than in East Asia. ${ }^{4}$ Data on the prevalence of a disease can differ remarkably depending on the study population, definition used, and study method (i.e., prospective vs. retrospective). The majority of previous studies have been single-center studies; however, few population-based studies, including those that utilized national data, have been reported thus far. ${ }^{5}$ A previous population-based study on a general population reported the

Received: April 25, 2018 Revised: May 16, 2018

Accepted: May 16, 2018

Correspondence: Hyuk Lee

Division of Gastroenterology, Department of Medicine, Samsung Medical Center, Sungkyunkwan University School of Medicine, 81 Irwon-ro Gangnam-gu, Seoul 06351, Korea

Tel: +82-2-3410-3409, Fax: +82-2-3410-6983, E-mail: leehyuk@skku.edu ORCID: https://orcid.org/0000-0003-4271-7205

(c) This is an Open Access article distributed under the terms of the Creative Commons Attribution Non-Commercial License (http://creativecommons.org/ licenses/by-nc/3.0) which permits unrestricted non-commercial use, distribution, and reproduction in any medium, provided the original work is properly cited. prevalence of eosinophilic esophagitis as $0.5-1$ patient per 1,000 individuals, similar to the prevalence of inflammatory bowel diseases, including Crohn's disease and ulcerative colitis. ${ }^{6,7}$ However, another population-based study from Sweden has reported a high prevalence of 4 patients per 1,000 individuals, which is likely because a patient from an asymptomatic group was thought to have eosinophilic esophagitis if $\geq 1$ eosinophilic infiltrations were observed under a high-magnification view. ${ }^{8}$ Aside from population-based studies, others have reported the prevalence of eosinophilic esophagitis in groups of patients who underwent endoscopic examination. ${ }^{4}$ Nonetheless, different indications for endoscopic examination in different studies resulted in varying prevalence values. In a prospective study, $6.5 \%$ of patients who underwent esophageal biopsy through endoscopy were diagnosed with eosinophilic esophagitis. However, the group of patients who underwent endoscopic examination owing to dysphagia showed a higher prevalence of $12 \%-22 \% .^{9-11}$ In addition, $1 \%-8 \%$ of patients with heartburn symptoms and $6 \%$ of patients with non-cardiac chest pain were diagnosed with eosinophilic esophagitis. ${ }^{12-14}$

The incidence rate of eosinophilic esophagitis is reported to be $6-13$ cases per 100,000 individuals. Previous studies have demonstrated a continuous increase in the incidence rate of eosinophilic esophagitis, especially those from the Western hemisphere; one report showed an increase from 9 cases per 100,000 individuals to 12.8 per 100,000 individuals over 3 years, and another report demonstrated an increase of 9.1 cases per 100,000 individuals over 5 years. ${ }^{4}$ A few hypotheses are suggested for the increase in the incidence rate of eosinophilic 
esophagitis. One is that the increased incidence rate is caused by an increased awareness of the disease. Clinicians performing endoscopic examinations have started to pay greater attention to eosinophilic esophagitis and perform active biopsies; consequently, the disease has been diagnosed more frequently. Direct evidence to support this hypothesis is the correlation between an increased frequency of endoscopic examination and an increased incidence rate of eosinophilic esophagitis. ${ }^{15}$ However, another study has shown that the incidence rate of eosinophilic esophagitis has increased by about 7 -fold, while the frequency of active biopsies performed has increased by only 2-3-fold, suggesting that an increased awareness of the disease is not the only reason for an increased incidence rate. ${ }^{16}$ Another hypothesis is that the frequent use of proton-pump inhibitors (PPIs) for the treatment of other diseases that may exhibit esophageal eosinophilia under biopsy reduces the incidence rate of gastroesophageal reflux disease (GERD), which can consequently reduce that of esophageal eosinophilia. Therefore, the increase in the incidence rate of eosinophilic esophagitis may be offset by this reduced incidence rate of GERD; overall, therefore, the increase in the incidence rate of esophageal eosinophilia observed under esophageal biopsy may not be significant. ${ }^{17}$

A study in this issue of Clinical Endoscopy assessed the prevalence of eosinophilic esophagitis in a group of patients with upper gastrointestinal symptoms from a region in Upper Egypt. ${ }^{18}$ The subjects who were treated with PPIs for 2 months but did not exhibit improvement in their upper gastrointestinal symptoms underwent endoscopic examination. Multiple biopsy samples were collected from 3 different regions $(5 \mathrm{~cm}$, $10 \mathrm{~cm}$, and $15 \mathrm{~cm}$ superior from the gastroesophageal junction); the patients were considered to have eosinophilic esophagitis if they exhibited $\geq 15$ eosinophils/high-powered field at any part of the esophagus. Only 4 patients who underwent endoscopic examination were diagnosed with eosinophilic esophagitis (prevalence rate, 1.87\%). In addition, 3 out of these 4 patients (75\%) diagnosed with eosinophilic esophagitis exhibited symptoms of dysphagia.

The prevalence values reported in this study accurately reflect the low prevalence of eosinophilic esophagitis in the Middle East or Asia as reported previously. ${ }^{4}$ Nevertheless, considering that the prevalence was obtained in a group of patients who underwent endoscopic examination owing to upper gastrointestinal symptoms, the prevalence value reported appears to be noticeably lower than in other typical reports. This may be because the patient group was composed of those who did not respond to PPI treatment. Clinically, eosinophilic esophagitis and PPI-responsive esophageal eosinophilia are not easily distinguishable, and it is still unclear whether the latter is a subtype of eosinophilic esophagitis or an outcome of GERD. ${ }^{19}$ The results from a meta-analysis demonstrate that $1 / 3$ of histologically suspected eosinophilic esophagitis cases showed clinical and histological improvement after PPI treatment. ${ }^{20}$ Recent opinions suggest that PPI-responsive esophageal eosinophilia is closer to a subtype of eosinophilic esophagitis than an outcome of GERD; therefore, the clinical and histological responses to PPI treatment should not be used as exclusion criteria for the diagnosis of eosinophilic esophagitis. ${ }^{21}$ Important evidence for this argument is that GERD can induce or aggravate eosinophilic esophagitis. Furthermore, PPI treatment itself may exhibit direct or indirect effects on allergic or immune pathways and suppress antigen expression in the esophageal lumen by improving epidermal defense of the esophageal mucous membrane. ${ }^{22}$ Consequently, PPI treatment can improve esophageal eosinophilia. For these reasons, the PPI-REE Task Force of the European Society of Eosinophilic Esophagitis suggests that the clinical guideline needs to be modified, and PPI treatment should be used for treatment rather than diagnostic purposes. ${ }^{23}$ In other words, this study by Fouad in Clinical Endoscopy may have included some patients who clearly had eosinophilic esophagitis, but were later excluded since they exhibited symptom improvement after PPI treatment. ${ }^{18}$ This ongoing debate on the definition of the subject group highlights the need for caution when analyzing the data regarding the prevalence of eosinophilic esophagitis. By performing endoscopic examination in all patients before and after PPI treatment, a more accurate assessment of the prevalence and characteristics of patients with eosinophilic esophagitis who respond to PPI treatment can be performed.

In conclusion, the prevalence of eosinophilic esophagitis in the patient group with upper gastrointestinal symptoms selected from the population of a small region in Egypta country in the Middle East-was extremely low at $1.87 \%$. However, since patients who exhibited improvement after PPI treatment were excluded, those with PPI-responsive esophageal eosinophilia may have also been excluded from this study. Therefore, this may cause differences in the reported prevalence of eosinophilic esophagitis.

Conflicts of Interest

The author has no financial conflicts of interest.

\section{REFERENCES}

1. Landres RT, Kuster GG, Strum WB. Eosinophilic esophagitis in a patient with vigorous achalasia. Gastroenterology 1978;74:1298-1301.

2. Attwood SE, Smyrk TC, Demeester TR, Jones JB. Esophageal eosinophilia with dysphagia. A distinct clinicopathologic syndrome. Dig Dis Sci 1993;38:109-116.

3. Cheng E, Souza RF, Spechler SJ. Tissue remodeling in eosinophilic esophagitis. Am J Physiol Gastrointest Liver Physiol 2012;303:G1175-G1187.

4. Dellon ES. Epidemiology of eosinophilic esophagitis. Gastroenterol Clin 
North Am 2014;43:201-218.

5. Lee H. Clinical review of eosinophilic esophagitis. Korean J Helicobacter Up Gastrointest Res 2018;18:3-12.

6. Dellon ES, Jensen ET, Martin CF, Shaheen NJ, Kappelman MD. Prevalence of eosinophilic esophagitis in the United States. Clin Gastroenterol Hepatol 2014;12:589-596.el.

7. Noel RJ, Putnam PE, Rothenberg ME. Eosinophilic esophagitis. N Engl J Med 2004;351:940-941.

8. Ronkainen J, Talley NJ, Aro P, et al. Prevalence of oesophageal eosinophils and eosinophilic oesophagitis in adults: the population-based Kalixanda study. Gut 2007;56:615-620.

9. Prasad GA, Talley NJ, Romero Y, et al. Prevalence and predictive factors of eosinophilic esophagitis in patients presenting with dysphagia: a prospective study. Am J Gastroenterol 2007;102:2627-2632.

10. Veerappan GR, Perry JL, Duncan TJ, et al. Prevalence of eosinophilic esophagitis in an adult population undergoing upper endoscopy: a prospective study. Clin Gastroenterol Hepatol 2009;7:420-426, 426.e1-e2.

11. Ricker J, McNear S, Cassidy T, et al. Routine screening for eosinophilic esophagitis in patients presenting with dysphagia. Therap Adv Gastroenterol 2011;4:27-35.

12. García-Compeán D, González González JA, Marrufo García CA, et al. Prevalence of eosinophilic esophagitis in patients with refractory gastroesophageal reflux disease symptoms: a prospective study. Dig Liver Dis 2011;43:204-208.

13. Rodrigo S, Abboud G, Oh D, et al. High intraepithelial eosinophil counts in esophageal squamous epithelium are not specific for eosinophilic esophagitis in adults. Am J Gastroenterol 2008;103:435-442.

14. Achem SR, Almansa C, Krishna M, et al. Oesophageal eosinophilic infiltration in patients with noncardiac chest pain. Aliment Pharmacol
Ther 2011;33:1194-1201.

15. Syed AA, Andrews CN, Shaffer E, Urbanski SJ, Beck P, Storr M. The rising incidence of eosinophilic oesophagitis is associated with increasing biopsy rates: a population-based study. Aliment Pharmacol Ther 2012;36:950-958.

16. Prasad GA, Alexander JA, Schleck CD, et al. Epidemiology of eosinophilic esophagitis over three decades in Olmsted County, Minnesota. Clin Gastroenterol Hepatol 2009;7:1055-1061.

17. Pyrsopoulos NT. Eosinophilic esophagitis: a comprehensive review. Journal of Hepatology and Gastrointestinal Disorders 2016;2:122.

18. Fouad M, Fouad YM, Mokareb HA, Mohamed EA, Abdel-Rehim DM. Prevalence of eosinophilic esophagitis in adult patients with upper gastrointestinal symptoms in a locality in upper Egypt. Clin Endosc 2018;51:357-361.

19. Dellon ES, Gonsalves N, Hirano I, Furuta GT, Liacouras CA, Katzka DA. ACG clinical guideline: evidenced based approach to the diagnosis and management of esophageal eosinophilia and eosinophilic esophagitis (EoE). Am J Gastroenterol 2013;108:679-692; quiz 693.

20. Molina-Infante J, Ferrando-Lamana L, Ripoll C, et al. Esophageal eosinophilic infiltration responds to proton pump inhibition in most adults. Clin Gastroenterol Hepatol 2011;9:110-117.

21. Kia L, Hirano I. Distinguishing GERD from eosinophilic oesophagitis: concepts and controversies. Nat Rev Gastroenterol Hepatol 2015;12:379386.

22. Wechsler JB, Bryce PJ. Allergic mechanisms in eosinophilic esophagitis. Gastroenterol Clin North Am 2014;43:281-296.

23. Molina-Infante J, Bredenoord AJ, Cheng E, et al. Proton pump inhibitor-responsive oesophageal eosinophilia: an entity challenging current diagnostic criteria for eosinophilic oesophagitis. Gut 2016;65:524-531. 